\title{
ANALISIS TEGANGAN ORIFICE CHAMBER YANG MENGALAMI LOKAL HOT SPOT DENGAN METODE ELEMEN HINGGA
}

\author{
Barkah Fitriyana $^{1, \mathrm{a}}$, Mustasyar Perkasa ${ }^{1,2, \mathrm{~b}}$, Ogi Ivano ${ }^{1, \mathrm{c}}$, Wahyu Sulistiyo ${ }^{1, \mathrm{~d}}$ \\ ${ }^{1}$ Balai BesarTeknologiKekuatanStruktur BPPT, Gd.220 PUSPITEK, Tangerang Selatan, Indonesia \\ ${ }^{2}$ Program StudiTeknikMesin, UniversitasPamulang, Jl.SuryaKencana No.1, Tangerang Selatan, Indonesia \\ E-mail : ${ }^{a}$ barkah.fitriyana@bppt.go.id; ${ }^{b}$ mustasyar.perkasa@bppt.go.id; \\ 'ogi.ivano@bppt.go.id; 'wahyu.sulistyo@bppt.go.id
}

Masuk : 24 Februari $2020 \quad$ Direvisi : 3 Maret $2020 \quad$ Disetujui : 21 Maret 2020

\begin{abstract}
Abstrak: Orifice chamber merupakan salah satu jenis dari bejana bertekanan. Dalam proses perancangan, dibutuhkan analisis tegangan yang dapat dilakukan dengan perhitungan secara analitis maupun numerik dengan metode elemen hingga. Selain untuk perancangan, analisis tegangan secara numerik juga dilakukan untuk orifice chamber yang mengalami cacat sesuai dengan CODE API 579-1/ASME FFS-1 Fitness for Service. Cacat yang bisa terjadi pada orifice chamber salah satunya berupa hot spot. Hot spot merupakan panas lokal yang terjadi di area tertentu pada struktur orifice chamber. Paper ini bertujuan untuk mengetahui kekuatan struktur orifice chamber yang mengalami lokal hot spot dengan analisis tegangan metode elemen hingga. Penelitian dilakukan dengan membuat pemodelan dan simulasi orifice chamber. Data temperatur hot spot didapatkan dari hasil pengukuran menggunakan fluke thermography. Hasil simulasi numerik pada orifice chamber di lokasi terjadinya hot spot berupa nilai tegangan yang lebih kecil dari tegangan ijin material sehingga struktur orifice chamber memenuhi kriteria keberterimaan dan aman untuk digunakan.
\end{abstract}

Kata kunci: Orifice chamber, analisis tegangan, hot spot, metode elemen hingga

Abstract: Orifice Chamber is one of pressure vessel equipment. In design process, stress analysis is needed and it can be done by analytical or numerical calculations using the finite element method. Beside for design process, numerical analysis also carried out for defect orifice chambers according to CODE API 579-1 / ASME FFS-1 Fitness for Service. One of the defects that occur at the orifice chamber is a hot spot. Hot spot is local heat that occurs in certain areas of the orifice chamber structure. This paper aims to determine the strength of the orifice chamber structure that experiences local hot spots by finite element method. The study was conducted by modeling and simulating the orifice chamber. Hot spot temperature data is collected from measurements using fluke thermography. The result of numerical simulations on the orifice chamber at the hot spot location is stress value smaller than allowable stressof material so that the orifice chamber structure meets the acceptance criteria and it safe to use.

Keywords: Orifice chamber, stress analysis, hot spot, finite element method 


\section{PENDAHULUAN}

Pada struktur orifice chamber mengalami hot spot pada bagian shell bagian atas seperti yang terlihat pada gambar 1. Temperatur tertinggi yang terukur pada daerah hot spot sebesar $460^{\circ} \mathrm{C}$. Daerah hot spot inilah yang akan diperiksa dengan analisis tegangan metode elemen hingga (FEM) untuk mengetahui kondisi struktur orifice chamber. Tujuan dari analisis tegangan yaitu untuk mengetahui data berupa nilai tegangan maksimum yang terjadi pada struktur orifice chamber yang mengalami hot spot. Struktur memenuhi kriteria aman jika hasil simulasi berupa tegangan maksimum yang terjadi pada orifice chamber masih berada di bawah nilai tegangan ijin (allowable stress) materialnya. Nilai tegangan ijin material didapatkan dari standar ASME Boiler And Pressure Vessel Code Section II Part D Properties metric.

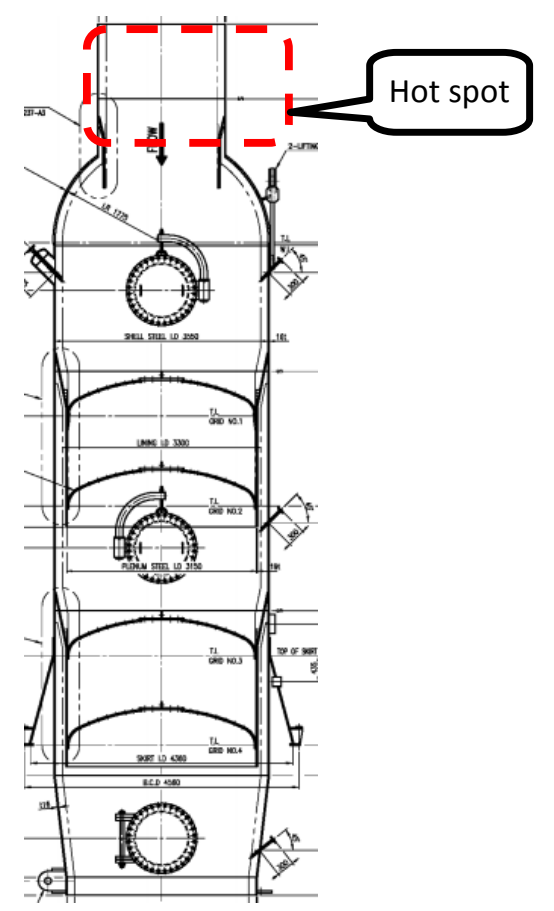

Gambar 1. Lokasi hot spot pada orifice chamber

Orifice chamber merupakan salah satu peralatan industri di bidang refinery atau perkilangan yakni pada sistem RFCC (Residual Fluid Catalytic Cracking) di mana minyak mentah sisa akan diolah lagi menjadi produk energi yang memiliki nilai jual yang tinggi. orifice chamber berfungsi untuk menurunkan tekanan fluida dengan menggunakan grid plate bertingkat yang dipasang di dalam shell orifice chamber. Pada perancangan orifice chamber, yang merupakan salah satu jenis bejana bertekanan (Pressure Vessel) biasanya memerlukan analisis tegangan yang dapat dilakukan secara analitis maupun numerik dengan metode elemen hingga [1]. Analisis tegangan dilakukan untuk memastikan bahwa orifice chamber yang dibuat telah memenuhi standar code tertentu dan aman untuk dioperasikan. Analisis tegangan dengan metode elemen hingga juga digunakan dalam pengkajian orifice chamber yang bermasalah atau cacat [2]. Permasalahan pada bejana bertekanan, termasuk orifice chamber dalam dunia industri diantaranya [3], yaitu:

- linier dan nonlinier, statik dan dinamis, analisa tegangan dan defleksi (STR)

- $\quad$ stabilitas (STA)

- $\quad$ thermal (THE)

- fraktur mekanik (FRA)

- $\operatorname{kontak}(\mathrm{CON})$

- fluida (FLU)

- manufaktur (MAN)

- $\quad$ pengelasan komponen PV (WEL)

- $\quad$ spesial metode elemen hingga untuk PV (ELE) 
Jurnal Teknik Mesin: CAKRAM 2020

Barkah Firiyana dkk, Analisis Tegangan Orifice Chamber yang Mengalami Lokal Hot Spot dengan Metode

Elemen Hinggga

- $\quad$ Software elemen hingga (SOF)

- Topik lain (OTH)

Topik thermal menjadi salah satu topik permasalahan yang sering terjadi, salah satunya hot spot. Hot spot berupa panas lokal yang terjadi pada daerah tertentu struktur dan merupakan suatu bentuk dari tegangan thermal lokal [4]. Hot spot terjadi pada bagian shell orifice chamber dengan spesifikasi orificechamber pada tabel 1.

Tabel 1. Spesifikasi teknis orifice chamber

\begin{tabular}{cc}
\hline Spesifikasi & Besaran dan Satuan \\
\hline Diameter dalam (ID) & $2100 \mathrm{~mm}$ \\
\hline Tebal & $16 \mathrm{~mm}$ \\
\hline Tekanan desain & $0.0358 \mathrm{kgf} / \mathrm{mm}^{2}$ \\
\hline Tekanan operasi & $0.00916 \mathrm{kgf} / \mathrm{mm}^{2}$ \\
\hline Temperatur desain & $788^{\circ} \mathrm{C}$ \\
\hline Temperatur operasi & $709^{\circ} \mathrm{C}$ \\
\hline
\end{tabular}

\subsection{Properti material}

\section{METODOLOGI}

Material yang digunakan pada orifice chamber terdiri dari 2 jenis, yaitu SA516 grade 70 pada bagian shell orifice chamber dan pliflow 3-24 pada bagian refractory. Detail properti material dapat dilihat pada tebel 2.

Tabel 2. Properti material orifice chamber

\begin{tabular}{cc}
\hline Properti & Besaran dan Satuan \\
\hline Material shell & SA516-70 \\
\hline densitas & $7750 \mathrm{~kg} / \mathrm{m}^{3}$ \\
\hline Tensile strength & $485 \mathrm{MPa}$ \\
\hline Yield strength & $260 \mathrm{MPa}$ \\
\hline Poisson ratio & 0,3 \\
\hline Material refractory & Pliflow 3-24 \\
\hline
\end{tabular}

\subsection{Kriteria Keberterimaan}

Sebagai Kriteria keberterimaan, nilai tegangan maksimum yang terjadi harus lebih kecil dari nilai tegangan ijin material. Tegangan ijin material SA516-70 [5] dapat dilihat padat tabel 3.

Tabel 3. Nilai tegangan ijin SA516-70 dengan Variasi Temperatur

\begin{tabular}{|c|c|c|}
\hline Temperatur $\left({ }^{\circ} \mathrm{C}\right)$ & Tegangan ijin (MPa) & Tegangan ijin $\left(\mathrm{kgf} / \mathrm{mm}^{2}\right)$ \\
\hline 200 & 150 & 15 \\
\hline 300 & 136 & 13.6 \\
\hline 400 & 101 & 10.1 \\
\hline 420 & 87 (Interpolasi) & 8.7 (Interpolasi) \\
\hline 425 & 83.8 & 8.38 \\
\hline 430 & 80.4 (Interpolasi) & 8.04 (Interpolasi) \\
\hline 450 & 66.8 & 6.68 \\
\hline 460 & 64.2 (Interpolasi) & 6.42 (Interpolasi) \\
\hline 475 & 50.3 & 5.03 \\
\hline 500 & 33.2 & 3.32 \\
\hline 525 & 21.4 & 2.14 \\
\hline 550 & 14.2 & 1.42 \\
\hline
\end{tabular}


Jurnal Teknik Mesin: CAKRAM 2020

Barkah Firiyana dkk, Analisis Tegangan Orifice Chamber yang Mengalami Lokal Hot Spot dengan Metode Elemen Hingga

\subsection{Geometri Model dan Boundary Condition}

Elemen yang digunakan dalam pemodelan orifice chamber yakni elemen pelat. Geometri model orifice chamber dapat dilihat pada gambar 2. Untuk posisi constraint berada pada lokasi paling bawah dari pemodelan. Pemodelan dilakukan dari atas head orifice chamber sampai pada ketinggian 5800 mm.

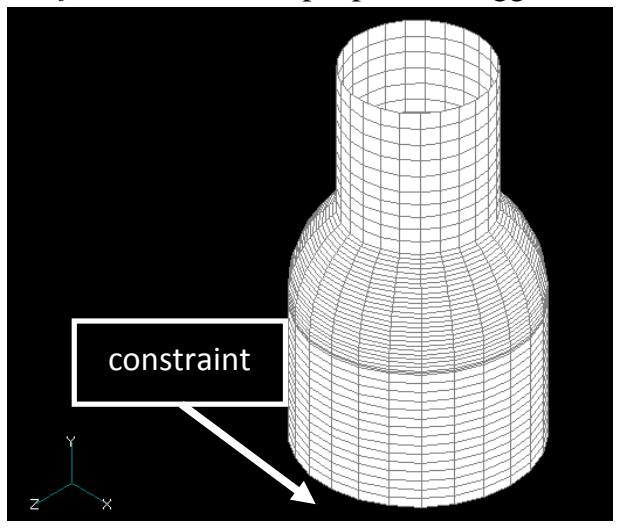

Gambar 2. Geometri model orifice chamber

\subsection{Pembebanan}

Pembebanan pada struktur orifice chamber meliputi beban-beban berikut ini :

1. Dead load (DL)

a. Dead Load Shell Plate(W1)

Tabel 4. Data perhitungan dead load shell

\begin{tabular}{cc}
\hline Spesifikasi & Besaran dan Satuan \\
\hline ID & $2100 \mathrm{~mm}$ \\
\hline Thickness & $16 \mathrm{~mm}$ \\
\hline Density $(\rho)$ & $7750 \mathrm{~kg} / \mathrm{m}^{3}$ \\
\hline Tinggi & $5800 \mathrm{~mm}$ \\
\hline
\end{tabular}

Perhitungan:

$L 1=\frac{1}{4} \pi d^{2}=\frac{1}{4} \pi(2100)^{2}=3461850 \mathrm{~mm}^{2}$

$L 2=\frac{1}{4} \pi d^{2}=\frac{1}{4} \pi(2132)^{2}=3568157.84 \mathrm{~mm}^{2}$

$L_{\text {total }}=L 2-L 1=(3568157.84-3461850) \mathrm{mm}^{2}=106307.84 \mathrm{~mm}^{2}$

$V=L_{\text {alas }} t=L_{\text {total }} t=\left(106307.84 \mathrm{~mm}^{2}\right)(5800 \mathrm{~m})=616585472 \mathrm{~mm}^{3}$

$m=\rho V=7750\left(10^{-9}\right) \frac{\mathrm{kg}}{\mathrm{mm}^{3}} \times 616585472 \mathrm{~mm}^{3}=4778.537 \mathrm{~kg}$

$W_{1}=m g=4778.537 \mathrm{~kg} \times 9.8 \frac{\mathrm{m}}{\mathrm{s}^{2}}=46829.66 \mathrm{~N}$

b. Dead load Refractory (W2)

Tabel 5. Data perhitungan dead load refractory

\begin{tabular}{cc}
\hline spesifikasi & Besaran dan Satuan \\
\hline ID & $1850 \mathrm{~mm}$ \\
\hline Thickness & $125 \mathrm{~mm}$ \\
\hline Density $(\rho)$ & $2400 \mathrm{~kg} / \mathrm{m} 3$ \\
\hline Tinggi refractory & $2230.8 \mathrm{~mm}$ \\
\hline
\end{tabular}


Jurnal Teknik Mesin: CAKRAM 2020

Barkah Firiyana dkk, Analisis Tegangan Orifice Chamber yang Mengalami Lokal Hot Spot dengan Metode Elemen Hinggga

$$
\begin{aligned}
& L 1=\frac{1}{4} \pi d^{2}=\frac{1}{4} \pi(1850)^{2}=2686662.5 \mathrm{~mm}^{2} \\
& L 2=\frac{1}{4} \pi d^{2}=\frac{1}{4} \pi(2100)^{2}=3461850 \mathrm{~mm}^{2} \\
& L_{\text {total }}=L 2-L 1=(3461850-2686662.5) \mathrm{mm}^{2}=775187.5 \mathrm{~mm}^{2} \\
& V=L_{\text {alas }} t=L_{\text {total }} t=\left(775187.5 \mathrm{~mm}^{2}\right)(2230.8 \mathrm{~m})=1729288.275 \mathrm{~mm}^{3} \\
& m=\rho V=2400\left(10^{-9}\right) \frac{\mathrm{kg}^{3}}{\mathrm{~mm}^{3}} \times 1729288.275 \mathrm{~mm}^{3}=4150.29 \mathrm{~kg} \\
& W_{2}=m g=4150.29 \mathrm{~kg} \times 9.8 \frac{\mathrm{m}}{\mathrm{s}^{2}}=40672.842 \mathrm{~N} \\
& \begin{array}{l}
\text { c. Dead Load total } \\
m_{\text {total }}=m_{1}+m_{2}=(4778.537+4150.29) \mathrm{kg}=8928.827 \mathrm{~kg} \\
W_{\text {total }}=W_{1}+W_{2}=(46829.66+40672.842) \mathrm{N}=87502.5 \mathrm{~N}
\end{array}
\end{aligned}
$$

\section{Pressure load (PL)}

Pressure load yang digunakan yaitu operating pressure sebesar $0.00916 \mathrm{kgf} / \mathrm{mm}^{2}$.

\section{Nozzle Load (NL)}

Nozzle Load yang digunakan adalah nozzle load pada kondisi operasi,dengan Fx sebagai nozzle load pada arah sumbu X, Fy sebagai nozzle load pada arah sumbu Y dan Fz sebagai nozzle load pada arah sumbu Z.

\begin{tabular}{cc}
\multicolumn{2}{l}{ Tabel 6. Nozzle load pada kondisi operasi } \\
\hline Nozzle load & Besaran dan Satuan \\
\hline Fx & $=-104.885 \mathrm{~N}$ \\
\hline $\mathrm{Fy}$ & $=-772.053 \mathrm{~N}$ \\
\hline $\mathrm{Fz}$ & $=70.929 \mathrm{~N}$
\end{tabular}

\section{Temperature load (TL)}

Temperature load yang digunakan berdasarkan hasil pengukuran menggunakan fluke thermography dengan lokal hot spot memiliki suhu maksimum $460^{\circ} \mathrm{C}$.
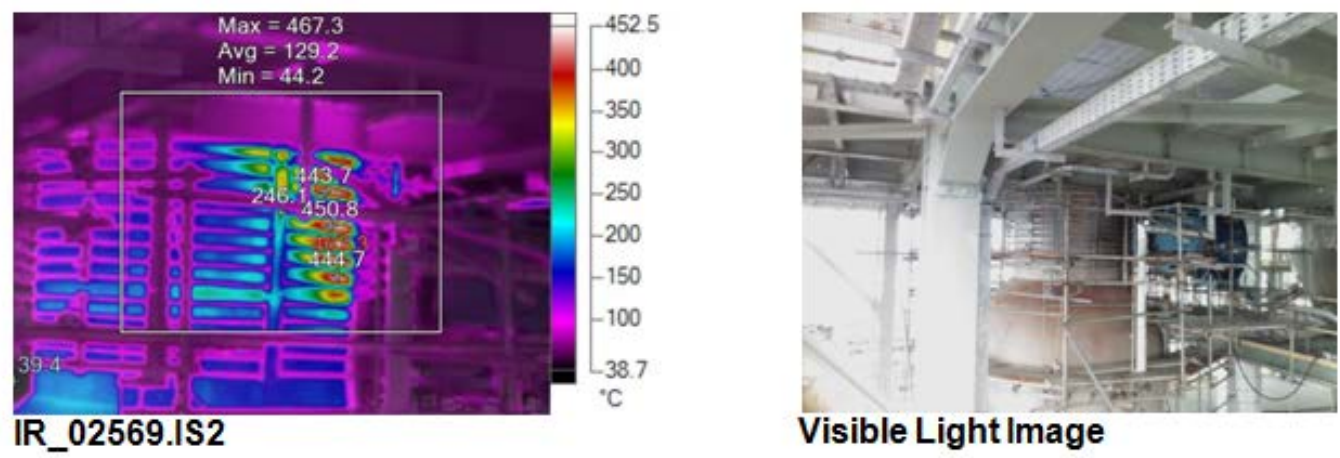

\section{Visible Light Image}

Gambar 3. Hasil pengukuran temperatur pada shell orifice chamber menggunakan fluke thermogrphy 


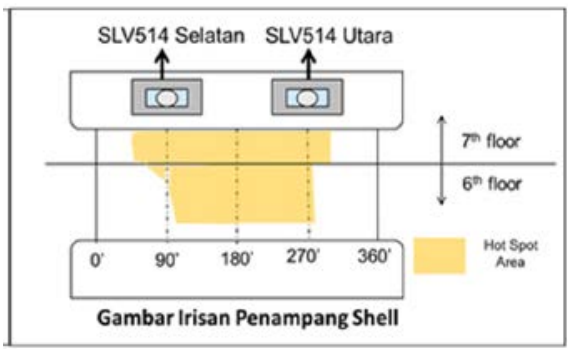

Gambar 4. Luasan hot spot area orifice chamber

Untuk lokasi masing-masing pembebanan dapat dilihat pada gambar 5.

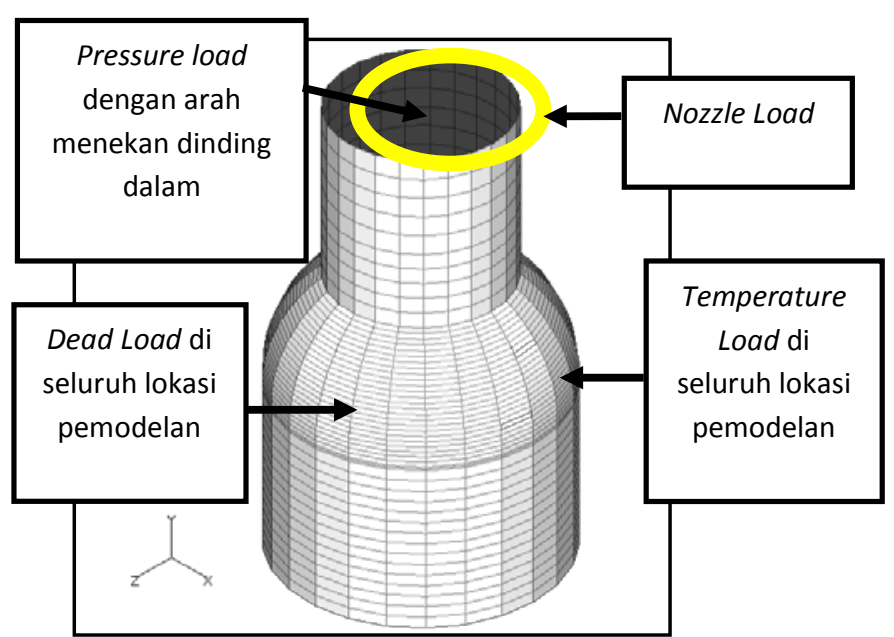

Gambar 5. Lokasi Masing-Masing Beban pada Orifice Chamber

\section{HASIL DAN PEMBAHASAN}

Hasil simulasi numerik pada struktur orifice chamber yang mengalami lokal hot spot dengan suhu maksimum $460{ }^{\circ} \mathrm{C}$ dan kombinas pembebanan dead load, pressure load, temperature load dan nozzle load $(\mathrm{DL}+\mathrm{PL}+\mathrm{TL}+\mathrm{NL})$ dapat dilihat pada gambar 6, 7 dan 8.

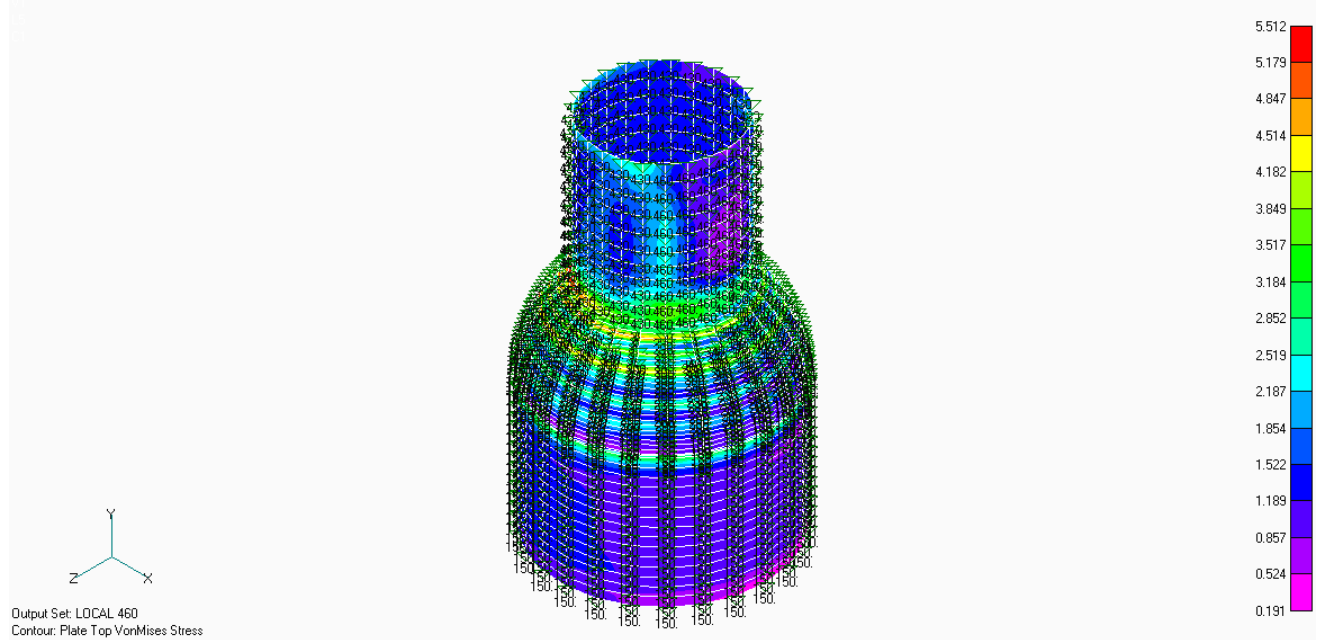

Gambar 6. Distribusi tegangan pada orifice chamber yang mengalami lokal hot spot dengan nilai tegangan maksimum $5.512 \mathrm{~kg} / \mathrm{mm}^{2}$. 

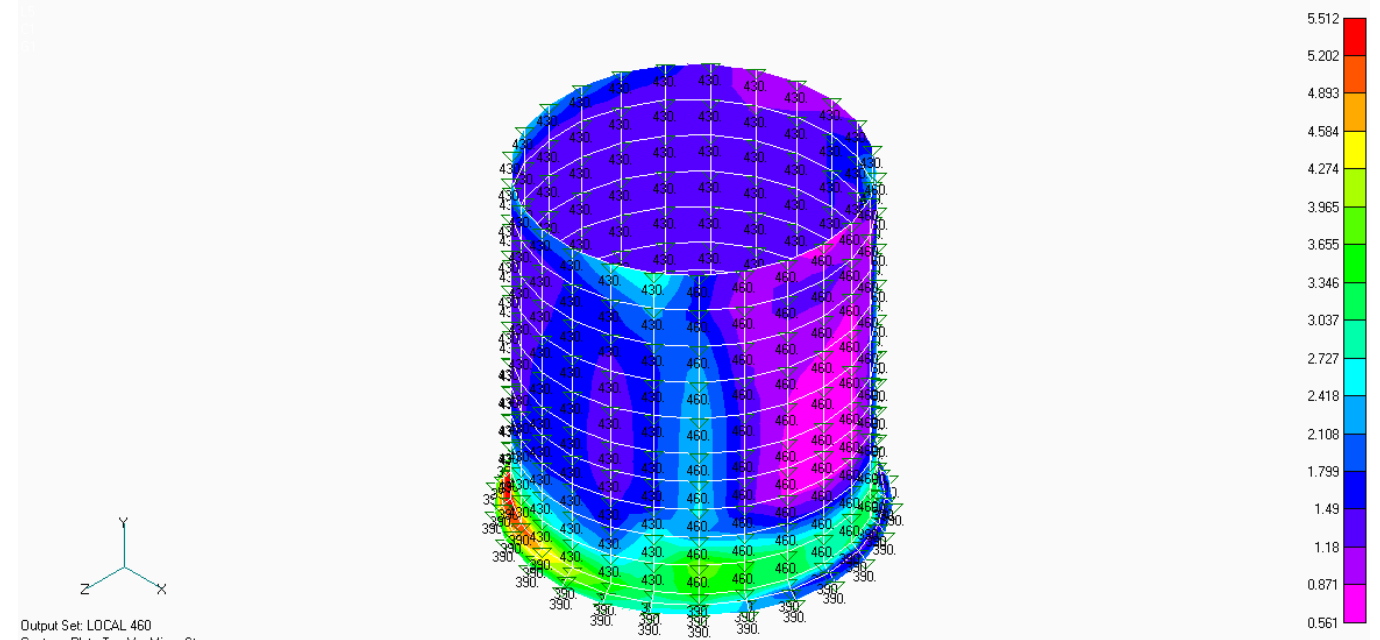

Gambar 7. Zoom Out distribusi tegangan pada orifice chamber yang mengalami lokal hot spot dengan nilai tegangan maksimum $5.512 \mathrm{~kg} / \mathrm{mm}^{2}$.

Gambar 6 memperlihatkan distribusi tegangan yang terjadi pada orifice chamber yang mengalami lokal hot spot dengan beban kombinasi dead load, pressure load, temperature load dan nozzle load dengan nilai tegangan maksimum $5.512 \mathrm{~kg} / \mathrm{mm}^{2}$. Tegangan maksimum yang terjadi diindikasikan pada area yang berwarna merah (red area). Tegangan maksimum ini terjadi pada daerah perbatasan elemen dengan suhu $390{ }^{\circ} \mathrm{C}$ dan 430 ${ }^{\circ} \mathrm{C}$. Nilai tegangan maksimum sebesar $5.512 \mathrm{~kg} / \mathrm{mm}^{2}$ lebih kecil jika dibandingkan dengan nilai tegangan ijin material yang besarnya $8.04 \mathrm{~kg} / \mathrm{mm}^{2}$ pada suhu $430{ }^{\circ} \mathrm{C}$.

Gambar 7 merupakan hasil zoom out dari distribusi tegangan pada orifice chamber, zoom out ini bertujuan untuk melihat detail pengaruh lokal hot spot $460{ }^{\circ} \mathrm{C}$ pada orifice chamber setelah pembebanan dead load, pressure load, temperature load dan nozzle load. Hasil zoom out memperlihatkan bahwa nilai tegangan yang terjadi pada daerah lokal hot spot diindikasikan dengan warna ungu, biru dan hijau dengan nilai tegangan maksimum pada warna hijau sebesar $4.274 \mathrm{~kg} / \mathrm{mm}^{2}$, nilai ini tentunya lebih kecil dibandingkan dengan nilai tegangan ijinmaterial yang besarnya $6.42 \mathrm{~kg} / \mathrm{mm}^{2}$ pada suhu $460{ }^{\circ} \mathrm{C}$. Sedangkan gambar 8 menggambarkan deformasi yang terjadi setelah kombinasi pembebanan dead load, pressure load, temperature load dan nozzle load yang telah disebutkan sebelumnya dengan nilai maksimum deformasi sebesar $6.496 \mathrm{~mm}$.
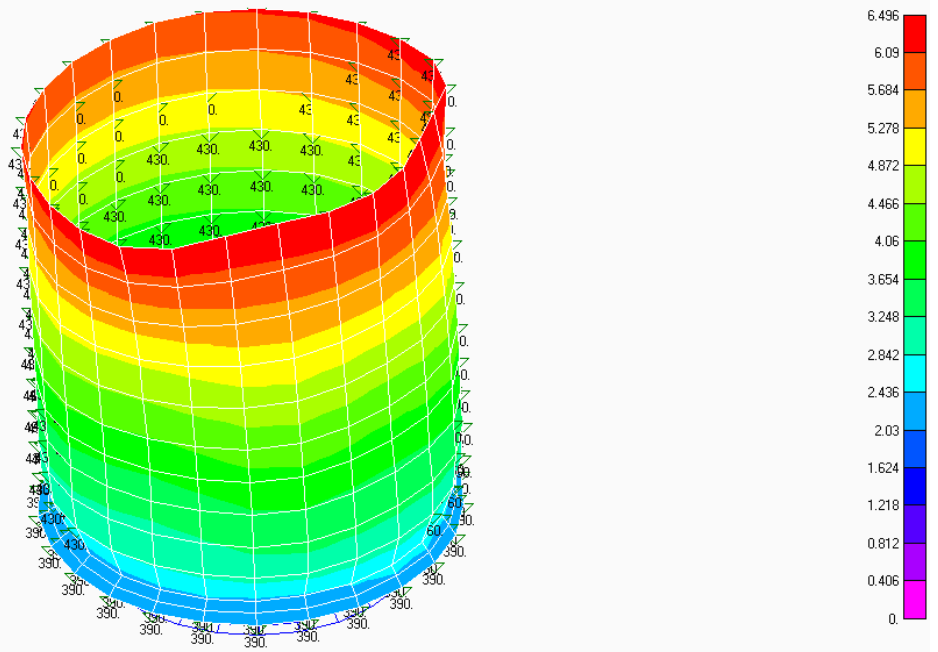

Gambar 8. Deformasi yang terjadi pada orifice chamber yang mengalami lokal hot spot dengan nilai deformasi $6.496 \mathrm{~mm}$. 


\section{KESIMPULAN}

- Hasil simulasi numerik global berupa tegangan maksimum di daerah necking orifice chamber sebesar 5.512 $\mathrm{kg} / \mathrm{mm}^{2}$ masih lebih kecil dibandingkan dengan tegangan ijin material yang besarnya $8.04 \mathrm{~kg} / \mathrm{mm}^{2}$ pada suhu $430{ }^{\circ} \mathrm{C}$.

- Hasil simulasi numerik berupa tegangan yang terjadi di area lokal hot spot sebesar $4.274 \mathrm{~kg} / \mathrm{mm}^{2}$ masih lebih kecil dibandingkan dengan nilai tegangan ijinmaterial yang besarnya $6.42 \mathrm{~kg} / \mathrm{mm}^{2}$ pada suhu $460{ }^{\circ} \mathrm{C}$.

- Struktur orifice chamber secara global dan lokal aman untuk beroperasi karena telah memenuhi kriteria keberterimaan.

\section{DAFTAR PUSTAKA}

[1] American Society of Mechanical Engineer. (2010). “ASME Boiler And Pressure Vessel Code Section VIII Division 22010 Edition”.New York : ASME International.

[2] American Petroleum Institute. (2007). “API 579-1/ ASME Fitness For Service-1 2nd Edition”.New York : ASME International.

[3] Mackerle, J., "Finite elements in the analysis of pressure vessels and piping, an addendum: A bibliography (2001-2004)”. International Journal of Pressure Vessels and Piping, 2005. 82(7): p. 571592.

[4] K. Xu, A. Alexander, T.S. Farma. (2018).” Management of Hot Spots in Refractory Lined High Temperature Equipment”. Praxair Ammonia Technical Manual.

[5] American Society of Mechanical Engineer. (2010). “ASME Boiler And Pressure Vessel Code Section II Part D Properties metric 2010 Edition”. New York : ASME International. 